\title{
Knowledge on HIV-AIDS and Practice of Sexual Behavior among High Risk Behavior Group in Saptari and Jhapa District, Nepal
}

\author{
Birendra Kumar Singh ${ }^{1 *}$ Dr. Dipak K. Bose ${ }^{1}$ Dr. Neena Gupta ${ }^{1}$ \\ Deelip Karki ${ }^{1}$ and Dilip Yadav ${ }^{1}$ \\ 1. Shalom Institute of Health \& Allied Sciences, SHUATS, Allahabad-211007(UP)
}

\begin{abstract}
The human immunodeficiency virus (HIV) is a retrovirus that infects cells of the immune system, destroying or impairing their function. The most advanced stage of HIV infection is acquired immunodeficiency syndrome (AIDS). Acquired Immune Deficiency Syndrome (AIDS) remains a public health problem of major significance in most parts of the world. The first HIV infection was detected in 1988 in Nepal. Since then HIV and AIDS epidemic has evolved from low to concentrated among "high risk behavior groups". The objective of this study was to find out knowledge on HIV-AIDS and assess the types of behavior that places them at risk of contracting HIV-AIDS in Saptari and Jhapa district of Nepal. This was the cross sectional descriptive study carried out among 457 high risk behavior groups, who come for treatment at VCT centres of both district. Multi stage sampling was adopted and data were collected using a pre-tested interview schedule. The study reported that majority of respondents (72.65\%) was fully correct about HIV and (73.30\%) about AIDS. Majority of respondents $(91.90 \%)$ had using condom. Around $36.54 \%$ reported to have undergone the initiation of experience sex much earlier at $<15$ years of age. More than half of the respondents $(56.02 \%)$ had used alcohol during sexual activity. Respondents had high practices $(96.50 \%)$ of condom use among the respondents who had knowledge about HIV. There is significant association between knowledge about HIV and practice of condom use (Cal $\chi 20.05,1=199.10>$ Tab $\chi 20.05,1, p=0.000$ ). Practice of addiction, injecting drugs without doctor's prescription, use of alcohol during sexual activity, negligence to use condom, early age at first sex, and use of intoxicating drugs were found the major types of behavior that places the respondents at risk of contracting HIV-AIDS. Based on the results of the study and experiences, it seems to conduct different activities as increase the awareness of HIV-AIDS to make high risk behavior groups aware from the comprehensive knowledge of transmission of HIV-AIDS, awareness program to promote safer sexual practices, Prevention programs for consistent use of condom, Free condom distribution programs through NGOs/ health workers/volunteers to cover the target population etc.
\end{abstract}

Keywords: HIV-AIDS, knowledge, practice, sexual behavior and high risk behavior group

\section{Introduction}

The human immunodeficiency virus (HIV) is a retrovirus that infects cells of the immune system, destroying or impairing their function. As the infection progresses, the immune system becomes weaker, and the person becomes more susceptible to infections. The most advanced stage of HIV infection is acquired immunodeficiency syndrome (AIDS). It can take 10-15 years for an HIV-infected person to develop AIDS; antiretroviral drugs can slow down the process even further. Globally, unprotected sexual intercourse between men and women is the predominant mode of transmission of the virus. Other important modes of transmission include unprotected penetrative sex between men, injecting drug use, and unsafe injections and blood transfusions and between a mother and her infant during pregnancy, childbirth and breastfeeding. [30]

Acquired Immune Deficiency Syndrome (AIDS) remains a public health problem of major significance in most parts of the world. Acquired Immune Deficiency Syndrome (AIDS) is the late stage of infection with a retro virus known as Human Immunodeficiency Virus (HIV). The first HIV infection was detected in 1988 in Nepal. Since then HIV and AIDS epidemic has evolved from low to concentrated among "High risk behavior groups" i.e. injecting drug users (IDUs), female sex workers (FSWs), men having sex with men (MSM) and seasonal labor migrants. High risk behavior groups are the most vulnerable groups for the contraction and transmission of HIV /AIDS and other STDs, not only due to their nature of work but also because of sexual relationships with rapidly changing multiple partners. [12]

In many countries, including most countries in the America, Asia and Europe, HIV infection is mainly concentrated in populations engaging in high-risk behavior, such as unprotected sex (particularly in the context of commercial sex work or between men) and sharing of drug injection equipment. In such situations, however, there is a persistent threat that localized epidemics will spill over into the wider population. In 
Knowledge on HIV-AIDS and practice of sexual behavior among high risk behavior group in ..

some countries, rapid growth of the size of the vulnerable population as a result of civil unrest, a rise in poverty or other social and economic factors triggers epidemic growth and wider spread of the virus. [31]

In context of Nepal, a large numbers of young Nepalese girls recruited as sex workers to Indian cities and a large numbers of young Nepalese males working in India are contributing to the increasing number of HIV infections. It is possible that within any society a subset of commercial sex workers (CSWs), with large number of unprotected sexual partners, could act as a core group of disease transmitters. [21]

According to the UN definition mentioned earlier, 44 per cent youth males and 28 per cent females in Nepal have comprehensive correct knowledge of HIV/AIDS in 2006. The figures for India were 36 and 20 per cent respectively for corresponding sexes (2005-06), 18 and 8 per cent in Bangladesh (2007), 50 and 42 per cent in Viet Nam (2005), 15 and 10 per cent in Indonesia (2007), 18 and 12 per cent in Philippines, highest of 62 and 65 per cent in Namibia (2007) and lowest of 5 per cent each in Azerbaijan (2006). Among African countries it is lowest in Mauritania (2007) with 14 and 5 per cent respectively (UN, 2011).

Individuals' knowledge of HIV transmission and accurate assessment of their own risk seem to be among the key factors in adoption of safer sexual practices. Therefore, study on knowledge on HIV-AIDS and practice of sexual behavior among high risk behavior groups is important in determining their sexual behavior which can lead them to vulnerable in contracting the HIV infection. One's correct knowledge or misconception about the infection may be an effecting factor for practicing safer or unsafe sexual activity. This study includes the examination of some selected socio-demographic factors affecting the correct knowledge about HIV-AIDS like having only one uninfected sex partner who has no other partners, always using condom during sex, and not having sex at all reduce the chance of getting HIV virus; a healthy looking person can have HIV virus; and one can get HIV virus from mosquito bites, by sharing foods with, and by touching infected person.

\section{Objective of the study}

1. To assess the knowledge regarding HIV-AIDS among the respondents.

2. To assess the types of behavior that places them at risk of contracting HIV-AIDS.

Null Hypothesis

1. $\mathrm{H}_{\mathrm{o}}$ : There was no association between knowledge regarding HIV-AIDS and high risk behavior of the respondents.

\section{Study design}

\section{Research Methodology}

It was a cross sectional descriptive study to study the knowledge/attitude on HIV-AIDS and to assess the sexual behavior among Female Sex Workers.

\section{Study area}

Saptari and Jhapa district was selected purposively as the study area, which is a terrain (plane area) district of Eastern Development Region of Nepal. There are three VCT centers (one in Saptari and two in Jhapa district) in these districts. All three VCT centers from both districts were selected purposively for the study purpose.

\section{Study population}

High risk behavior groups (female sex workers-FSWs, clients of FSWs, men sex with men (MSM) and injecting drug users (IDUs) who come for treatment at VCT centres of both Saptari and Jhapa district were the population of study.

\section{Sample and sampling procedure}

The sample size was calculated by using the following formula.

$\mathrm{n}=\mathrm{z}^{2} \mathrm{pq} / \mathrm{e}^{2}$

$\mathrm{n}=$ no. of respondents

$\mathrm{Z}=1.96$ for 98 per cent confidence interval

$\mathrm{P}=$ prevalence 5 per cent ( $5 \%$ estimated HIV prevalence among Clients of Sex worker)

$\mathrm{q}=1-\mathrm{p}$

$\mathrm{e}=$ standard error $(2 \%)$

$$
\mathrm{n}=\quad \begin{aligned}
& (1.96)^{2} * 0.05 * 0.95 \\
& \ldots \ldots \ldots \ldots \ldots \ldots \ldots \ldots \ldots \ldots \ldots \ldots \ldots
\end{aligned} \quad=456.19
$$

Total selected sample size: $\mathbf{4 5 7}$

Final sample size: $\mathbf{4 5 7}$ 
Knowledge on HIV-AIDS and practice of sexual behavior among high risk behavior group in ..

\section{Sampling procedure:}

A total of 457 samples were selected from the list of three VCT centres. All the high risk behavior groups visiting at VCT centers were interviewed till the required number of sample size was met.

\section{Methods of data collection}

Interview method was adopted to collect data for the study. Pre structured interview schedule was used for interview. Informed verbal consent from the respondents was taken.

\section{The use of statistical test in research}

Data coding and editing was done manually. Entry and analysis was done by using SPSS version 16.0. The use of statistical tests like Mean, Median, Range, Chi-square test, P-value and Odds Ratio was used to analyze the data.

\section{Results And Discussion}

\subsection{Socio demographic characteristics}

The study shows that there were $(43.76 \%)$ female sex workers, $(23.42 \%)$ clients of FSWs, $(21.88 \%)$ injecting drug users and (10.94\%) men having sex with men. About two third of respondents $(65.21 \%)$ were in urban settlement. Average age of the respondents was 24.80 years with S.D. of 4.14. Less than two third of respondents $(61.49 \%)$ were in 20-30 year age group and more than three fourth of respondents $(85.12 \%)$ were literate. More than two third of respondents (70.24\%) were drinking alcohol and only (31.29 \%) of the respondents were having intoxicating drugs like Charas, Ganja, Bhang. 23.98 per cent respondents were injecting drug without doctor's prescription and more than half of the respondents (52.95\%) have RTI problems.

\subsection{Knowledge about HIV and AIDS}

Puwar et al. (2015) revealed that 85 per cent High Risk Groups knew about HIV and 76 per cent about AIDS. All IDUs had heard of HIV/ AIDS as per IBBS, 2011.

The present study showed maximum number of respondents $(72.65 \%)$ was fully correct about HIV and only 6.12 per cent respondents were not correct about HIV. Maximum no. of respondents (73.30 \%) was fully correct about AIDS and only 0.88 per cent respondents were not correct about AIDS. About half of the respondents $(48.58 \%)$ were fully correct about reading AIDS education material followed by $(28.88 \%)$ partially correct and $(22.54 \%)$ not correct. More than half of the respondents $(58.42 \%)$ was fully correct about AIDS is sexually transmitted disease. Only $(26.04 \%)$ respondents were fully correct about HIV is the causative agent of AIDS and more than half of the respondents $(55.36 \%)$ was not correct. Only (17.07 \%) respondents were fully correct about correct full form of the HIV-AIDS and majority of the respondents $(61.70 \%)$ was not correct (Table No. 1.1).

Table No. 1.1 Knowledge about HIV and AIDS

\begin{tabular}{|c|c|c|c|}
\hline Variables & Category & Frequency & Percentage \\
\hline \multirow[t]{3}{*}{ i. Heard about HIV } & Fully correct & 332 & 72.65 \\
\hline & Partially correct & 97 & 21.23 \\
\hline & Not correct & 28 & 6.12 \\
\hline \multirow[t]{3}{*}{ ii. Heard about AIDS } & Fully correct & 335 & 73.30 \\
\hline & Partially correct & 118 & 25.82 \\
\hline & Not correct & 4 & 0.88 \\
\hline \multirow[t]{3}{*}{ iii. Ever read AIDS education materials } & Fully correct & 222 & 48.58 \\
\hline & Partially correct & 132 & 28.88 \\
\hline & Not correct & 103 & 22.54 \\
\hline \multirow[t]{3}{*}{ iv. AIDS is a sexually transmitted disease } & Fully correct & 267 & 58.42 \\
\hline & Partially correct & 142 & 31.07 \\
\hline & Not correct & 48 & 10.50 \\
\hline \multirow[t]{3}{*}{ v. HIV is causative agent of the disease AIDS } & Fully correct & 119 & 26.04 \\
\hline & Partially correct & 85 & 18.60 \\
\hline & Not correct & 253 & 55.36 \\
\hline \multirow[t]{3}{*}{ vi. Know correct full form of HIV-AIDS } & Fully correct & 78 & 17.07 \\
\hline & Partially correct & 97 & 21.23 \\
\hline & Not correct & 282 & 61.70 \\
\hline
\end{tabular}

(Primary source) 
Knowledge on HIV-AIDS and practice of sexual behavior among high risk behavior group in ..

\subsection{Practice of sexual risk behavior}

Khaniya and Joshi (2004) revealed that all of the respondents had used condom last time. For majority of the respondents, it is the client who provides the condom. The frequency of condom use was satisfactory. Majority of the respondents said that they use alcohol during sexual activity. Among the alcohol users, majority of the respondents replied that they had never forget to use condom because they had alcohol and only 4 per cent neglected to use condom because they had have alcohol. This figure gives a clue that the respondents showed risky sexual behavior.

The present study showed average age at the initiation of sex was 16.28 years with S.D. of 2.9. Sex at an early age was the prevalent practice among the study population as 93.22 per cent of them reported to have initiated sex before the age of 20 years. Around 36.54 per cent reported to have undergone the experience much earlier at $<15$ years of age and only 6.78 per cent had initiated after the age of 20 years.

The study also found maximum no. of respondents $(91.90 \%)$ had using condom. Majority of respondents $(64.11 \%)$ had used condom every time and $(27.79 \%)$ sometimes. More than half of the respondents $(56.02 \%)$ had used alcohol and less than half $(43.98 \%)$ had not used alcohol during sexual activity. Where only $(10.72 \%)$ respondents had used alcohol every time and majority respondents $(45.30 \%)$ used alcohol sometimes. More than one third of respondents or sexual partners $(40.04 \%)$ had refused to use condom and less than two third $(59.96 \%)$ had not refused to use condom in the last 3 months. About $(12.47 \%)$ respondents had failed to persuade when respondents or their partners refused to use condom followed by (13.79 $\%)$ had persuaded successfully, (7.43\%) refused to have sex and $(6.35 \%)$ charged extra amount (Table No. $1.2)$.

Table No. 1.2 Knowledge about HIV and AIDS

\begin{tabular}{|c|c|c|c|}
\hline Variables & Category & Frequency & Percentage \\
\hline \multirow{2}{*}{ i. Use of condom } & Yes & 420 & 91.90 \\
\hline & No & 37 & 8.10 \\
\hline \multirow[t]{3}{*}{ ii. Frequency of condom use } & Every Time & 293 & 64.11 \\
\hline & Sometimes & 127 & 27.79 \\
\hline & Not responded & 37 & 8.10 \\
\hline \multirow[t]{2}{*}{ iii. Use of alcohol during sexual activity } & Yes & 256 & 56.02 \\
\hline & No & 201 & 43.98 \\
\hline \multirow{3}{*}{$\begin{array}{l}\text { iv. Frequency of use of alcohol during sexual } \\
\text { activity }(\mathrm{N}=256)\end{array}$} & Every time & 49 & 10.72 \\
\hline & Sometimes & 207 & 45.30 \\
\hline & Not responded & 201 & 43.98 \\
\hline \multirow{2}{*}{$\begin{array}{l}\text { v. Sexual partners refused to use condom in the } \\
\text { last } 3 \text { months }\end{array}$} & Yes & 183 & 40.04 \\
\hline & No & 274 & 59.96 \\
\hline \multirow{5}{*}{$\begin{array}{l}\text { vi. Action taken when partner refused to use a } \\
\text { condom }\end{array}$} & Refused to have sex & 34 & 7.43 \\
\hline & Charged extra amount & 29 & 6.35 \\
\hline & Persuaded successfully & 63 & 13.79 \\
\hline & Failed to persuade & 57 & 12.47 \\
\hline & Not responded & 274 & 59.96 \\
\hline
\end{tabular}

\subsection{Relationship between Knowledge on HIV-AIDS and Practice of Sexual Behavior}

The present study revealed that among the respondents who had knowledge about HIV, high practices $(96.50 \%)$ of condom use was reported as compared to only (21.40\%) of condom use among the respondents who did not know about HIV. There is significant association between knowledge about HIV and practice of condom use $(\mathrm{Cal} \chi 20.05,1=199.10>$ Tab $\chi 20.05,1, \mathrm{p}=0.000)$. Practice of condom use was affected by knowledge about HIV. Practice of condom use among the respondents who knowledge about HIV was 101.20 times more than the respondents who did not know about HIV. Hence Ho hypothesis was rejected and research hypothesis was accepted (Table No. 1.3).

Table No. 1.3 Knowledge about HIV and Use of condom

\begin{tabular}{|c|c|c|c|}
\hline \multirow[t]{2}{*}{ Knowledge about HIV } & \multicolumn{2}{|c|}{ Use of condom } & Total \\
\hline & Yes & No & \\
\hline Yes & 414 (96.50) & $15(3.50)$ & $429(100.0)$ \\
\hline No & $6(21.4)$ & $22(78.6)$ & $28(100.0)$ \\
\hline Total & $420(91.9)$ & $37(8.1)$ & $457(100.0)$ \\
\hline
\end{tabular}

Note: The figure in the parenthesis is percentage of frequency.

The present study revealed that among the respondents who had knowledge about HIV, low practices $(37.10 \%)$ of rejection of condom use was reported as compared to $(85.70 \%)$ among the respondents who did not know about HIV. There is significant association between knowledge about HIV and practice of rejection of 
Knowledge on HIV-AIDS and practice of sexual behavior among high risk behavior group in ..

condom use $(\mathrm{Cal} \chi 20.05,1=25.91>\mathrm{Tab} \chi 20.05,1, \mathrm{p}=0.000)$. Practice of rejection of condom use was affected by knowledge about HIV. Hence Ho hypothesis was rejected and research hypothesis was accepted.

Table No. 1.4 Knowledge about HIV and Sexual partner refused to use condom

\begin{tabular}{|l|c|c|c|}
\hline \multirow{2}{*}{ Knowledge about HIV } & \multicolumn{1}{|c|}{ Sexual partner refused to use condom } & Total \\
\cline { 2 - 4 } & Yes & No & \\
\hline Yes & $159(37.10)$ & $270(62.90)$ & $429(100.0)$ \\
\hline No & $24(85.70)$ & $4(14.30)$ & $28(100.0)$ \\
\hline Total & $183(40.00)$ & $274(60.00)$ & $457(100.0)$ \\
\hline Cal $\chi_{0.05,1}^{2}=25.91, \quad$ pab $\chi_{0.05,1}^{2}=3.84, \quad 0.000$ & Significant \\
\hline
\end{tabular}

Note: The figure in the parenthesis is percentage of frequency.

\section{Conclusion}

\section{Conclusion and Recommendation}

A cross sectional descriptive study which was done among 457 High risk behavior group concludes that

1. More than two third of respondents $(70.24 \%)$ were drinking alcohol.

2. About half of respondents $(51.20 \%)$ had addiction.

3. Only $(22.98 \%)$ respondents were injecting drug without doctor's prescription.

4. Majority of respondents (72.65\%) was fully correct about HIV and (73.30\%) about AIDS.

5. Majority of respondents $(91.90 \%)$ had using condom. Around $36.54 \%$ reported to have undergone the initiation of experience sex much earlier at $<15$ years of age. The median age at first experience was 16.28 years with S.D. of 2.9 .

6. Majority of respondents had using condom and more than two third (64.11\%) used condom consistently.

7. More than half of the respondents $(56.02 \%)$ had used alcohol during sexual activity.

8. Respondents had high practices $(96.50 \%)$ of condom use among the respondents who had knowledge about HIV.

9. There is significant association between knowledge about HIV and practice of condom use (Cal $\chi 20.05,1=$ $199.10>\mathrm{Tab} \chi 20.05,1, \mathrm{p}=0.000)$. Practice of condom use was affected by knowledge about HIV.

10. There is significant association between knowledge about HIV and practice of rejection of condom use (Cal $\chi 20.05,1=25.91>$ Tab $\chi 20.05,1, p=0.000)$. Practice of rejection of condom use was affected by knowledge about HIV. Hence Ho hypothesis was rejected and research hypothesis was accepted.

\section{Recommendation}

1. HIV-AIDS awareness program needs to be more focused in order to promote safer sexual practices.

2. HIV-AIDS prevention programs should be focused more on the need for consistent use of condom for HIV/STI infection prevention.

3. There is need for Free condom distribution programs through NGOs/ health workers/ volunteers.

4. Conduction of intensive education campaigns to change the types of behavior that places them at risk of contracting HIV_AIDS, and the image of condom as a sign of caring of health.

5. A module on HIV-AIDS and high risk sexual behavior to be developed by the Government in consultation with concerned NGOs \& INGOs and implements that module through them to enhance knowledge and practices of HRSBGs.

6. Practice of addiction, injecting drugs without doctor's prescription, use of alcohol during sexual activity, negligence to use condom, early age at first sex are playing significant role in RTIs problems, HIV-AIDS, health education on HIV-AIDS and condom promotion need to be promoted and types of behavior that places the respondents at risk of contracting HIV-AIDS be abandoned by using various IEC activities.

\section{Acknowledgements}

Foremost I thank the Almighty God for his presence and for his helping hand whenever I need Him throughout this study. I express my deep gratitude to my advisor Dr. Dipak Kumar Bose, Associate professor (Sr.), Dr Neena Gupta, Assistant professor (Sr.), SHUATS, Allahabad, for her valuable suggestions and continuous encouragement that this study was made possible.

No words are enough to express my deep sense of gratitude and love to my parents shree Utim Lal Mahato and Late Aasha Devi who devoted their entire life for my success and untiring efforts and good wishes to materialization this dream. Furthermore, heartful thanks go to my lovely wife Mrs. Renu Kumari Singh and daughter Barshika Singh for giving moral support, and inspirations of my life. 


\section{References}

[1]. Alene G.D. (2002). Knowledge and practice of condom in preventing HIV/AIDS infection among commercial sex workers in three small towns of northwestern Ethiopia. Ethiopia Journal of Health Development.16 (3):pp.277-286

[2]. Banjade B., Patil S., Naik V.A., Basavagouda A., Narasannavar, Shrestha A. (February 2015). Knowledge, attitude and practice about HIV/AIDS among men who have sex with men in Belgaum: A cross-sectional study. International Journal of Medicine and Public Health. Jan-Mar 2015 Vol 5 Issue 1 pp24-28

[3]. Behringer. (2010). HIV-AIDS Prevention: Factors Affecting Risky Sexual Behaviors among MSM in Shenzhen, China (2008). UCHC(University of Connecticut Health Center) Graduate School Masters Theses. http://digitalcommons.uconn.edu/uchcgs_masters/pp.144
Bhatta D.N. (2014). HIV-related sexual risk behaviors among male-to-female transgender people in Nepal. International Journal of Infectious Diseases, Volume.22, pp. 11-15.

[5]. Bhatta P, Thapa S, Neupane S, Baker J, and Friedman M. (1994). Commercial Sex Workers in Kathmandu Valley: Profile and Prevalence of Sexually Transmitted Diseases. JNMA (Journal of Nepal Medical Association); 32:192-203

[6]. CREHPA (Center for Research on Environment Health and Population activities). (2005). Integrated Bio-behavioral Survey (IBBS) among MSM Population in Kathmandu Valley. E-mail: crehpa@crehpa.wlink.com.np

[7]. Central intelligence agency, The world fact book. Available: https://www.cia.gov/library/publications/the-worldfactbook/geos/np.html

[8]. Chaudhry M. A., Naeem M., Iqbal R., and Shabbir I. (Jan-June, 2005). Level of awareness about HIV-AIDS among truck drivers and their attitude towards persons with AIDS. Gomal Journal of Medical Sciences, Vol.3, No.1.pp.19-23.

[9]. Chauhan T., Bhardwaj A.K., Parashar A. and Kanga A.K. (2013). A study of Knowledge, Attitude, Behaviour and Practice (KABP) among the attendees of Integrated Counselling and Testing Centre of Tertiary Care Hospital of Northern Hilly State of India. Al Ameen Journal of Medical Science, 6(3):265-271.

[10]. Family Health International/Nepal. (June - August 2008). Integrated Biological and Behavioral Surveillance Survey among Female Sex Workers in Pokhara Valley - Round III.

[11]. FHI/New Era and SACTS.IBBS Fact http://www.fhi.org/en/CountryProfiles/Nepal/res_IBBS_Nepal.htm FHI/New Era SACTS. (2000). Integrated Bio-Behavioral Survey among Female Sex Workers in East-West Highways Covering 22 Districts of Nepal. Pyukha, Kathmandu;

[12]. Government of Nepal, Ministry of Health and Population, NCASC, Teku. (2010). HIV and STI Prevalence Declining among Certain Most-at-Risk Populations in Nepal. [web page on the internet]. 2009-09-17 http://www.ncasc.gov.np/pressrelease.php?id=5

[13]. Gupta S., Khanal T.R., Gupta N., Thakur A., Khatri R., Suwal A., and Seomangal K. (2011). Knowledge, Behavior and Attitude towards Sexually Transmitted Infections and Acquired Immunodeficiency Syndrome of Adolescent Students. Journal of Nepal Health Research Council 2011 April;9(18):44-47.

[14]. Gurung G. (October 2004). Knowledge and Attitude on HIV/ AIDS and Sexual Behavior of Street Teenagers in Kathmandu Valley. Journal of Nepal Health Research Council Vol. 2 No. 2.pp.9-13

[15]. Karki T.B. (2014). Correlation between Knowledge, Attitude and Practices on HIV and AIDS: Cases from the Kathmandu Valley. Journal of Nepal Health Research Council;12(26):24-29.

[16]. Khaniya R. and Joshi A.B. (2 October 2004). Sexual Behavior and Risk Perception of HIV/AIDS among Female Sex Workers (FSWS) in Kathmandu City, Nepal. Journal of Nepal Health Research Council Vol. 2 No. pp. 60-61.

[17]. Lothe E., and Dr. Gurung M. (2007). HIV/AIDS Knowledge, Attitude and Practice survey: UN Uniformed Peacekeepers in Haiti. United Nation Peace Keeping in the service of peace.

[18]. Maimaiti N., Shamsuddin K., Abdurahim A. Tohti N., and Memet R. (2010). Knowledge, Attitude and Practice regarding HIV/AIDS among University students in Xinjiang. Global Journal of Health Science, Vol 2, No 2. ISSN 1916-9744.

[19]. Matovu J.K.B., Ssebadduka N.B. (2013). Knowledge, attitudes and barriers to condom use among female sex workers and truck drivers in Uganda: a mixed-method study. African Health Sciences, Vol 13, Issue 4 pp 1027-1033

[20]. NCASC and ASHA Project (2011). Integrated Biological and Behavioral Surveillance (IBBS) Survey among Injecting Drug Users in Pokhara Valley, Nepal, Round V-2011.

[21]. NCASC and ASHA project (2011). Integrated Biological and Behavioral Surveillance (IBBS) Survey among Female Sex Workers in Kathmandu Valley, Nepal, Round IV-2011.

[22]. NCASC (2015). Integrated Biological and Behavioral Surveillance (IBBS) Survey among female sex workers (FSWs) in Kathmandu Valley, Round V -2015.

[23]. NCASC (2015). Integrated Biological and Behavioral Surveillance (IBBS) Survey among Men Who have Sex with Men (MSM) and Transgender (TG) in Kathmandu Valley Round V -2015.

[24]. NCASC (2015). Integrated Biological and Behavioral Surveillance (IBBS) Survey among People Who Inject Drugs in the Eastern Terai of Nepal Round VI -2015.

[25]. New Era. (2007). Integrated Bio-behavioral Survey (IBBS) among Men who have Sex with Men in the Kathmandu Valley. In Collaboration with STD/AIDS Counseling and Training Services-Pyukha, Kathmandu, Nepal.

[26]. Oli N.L., Onta S.R., Dhakal S. (2012). Knowledge about HIV transmission, behavior and self perception about risk of getting HIV among men. Journal of Institute of Medicine,32:2 pp4-9

[27]. Puwar B.T., Patel V., Vyas S., Oza U., Kapoor R. (2015). Knowledge about transmission and prevention of HIV/AIDS among the high risk groups (HRG) population of Ahmedabad city. NHL Journal of Medical Sciences/Vol 4/issue 1

[28]. Rana M.S., Nepali B., Sathian B., Aryal R.P., Thapalia M., Bhatta D.R. (2013). The Socio-demographic characteristics of the clients of female sex workers and their perspectives, behaviors and attitude on HIV and AIDS: A questionnaire based survey from pokhara, Nepal. Journal of Clinical and Diagnostic Research, Vol 7 (1):112-117

[29]. The World Bank. (2008). HIV/AIDS in Nepal. The World Bank, Washington, DC

[30]. WHO. HIV/AIDS. [webpage on the internet]. [accessed on October 2010] http://www.who.int/topics/hiv_infections/en/index/html

[31]. WHO. HIV / AIDS in the South-East Asia Region. WHO, Geneva; 2009 